\title{
The birth prevalence rates for the skeletal dysplasias
}

\author{
IEDA M ORIOLI*, EDUARDO E CASTILLA†, AND \\ JOÃO G BARBOSA-NETO \\ From *the Department of Genetics, Institute of Biology, Federal University of Rio de Janeiro, Brazil; \\ †Instituto Multidisciplinario de Biologia Celular (IMBICE), La Plata, Argentina; and $¥$ Section of Medical \\ Genetics, Department of Pediatrics, Hospital dos Servidores do Estado, Rio de Janeiro, Brazil.
}

SUMmARY This study was undertaken to establish the prevalence rates at birth of the skeletal dysplasias that can be recognised in the perinatal period. Using the data base of the Latin-American Collaborative Study of Congenital Malformations (ECLAMC), for the years 1978 to 1983 , on 349470 births (live and stillbirths), a crude prevalence rate of 2.3/10 000 was observed. However, several indications of under-registration suggest that the real value is about twice that observed. The most frequent types of skeletal dysplasia were achondroplasia, with a prevalence rate between 0.5 and $1.5 / 10000$ births, the thanatophoric dysplasia/achondrogenesis group ( 0.2 and $0 \cdot 5 / 10000$ births), and osteogenesis imperfecta $(0 \cdot 4 / 10000$ births). The mutation rate for autosomal dominant achondroplasia was estimated at between 1.72 and $5 \cdot 57 \times 10^{-5}$ per gamete per generation.

In published reports, two different prevalence rates at birth of the skeletal dysplasias can be found: $4 \cdot 7 / 10000$ reported by Gustavson and Jorulf, ${ }^{1}$ and a lower figure of $2 \cdot 4 / 10000$ given by Camera and Mastroiacovo. ${ }^{2}$ The latter authors stated that their figure should be closer to reality due to the larger size of their birth sample, which was obtained through a multicentre, hospital based programme.

The study presented here aimed to analyse the birth prevalence rates for the skeletal dysplasias, and to estimate its under-ascertainment, using the material of another multi-hospital birth defects registry: the Latin-American Collaborative Study of Congenital Malformations (ECLAMC) ${ }^{3}$

\section{Material and methods}

A total of 349470 births (343890 live and 5580 stillbirths) were examined prospectively in 26 maternity hospitals in 20 different cities of nine South American countries (Argentina, Bolivia, Brazil, Chile, Colombia, Ecuador, Peru, Uruguay, and Venezuela) during their participation in the ECLAMC programme from 1978 to 1983 . The ECLAMC is a hospital based, clinicalepidemiological, case control study of birth defects, the methodological details of which have been published. ${ }^{3}$ All babies are examined by a paediatrician and the malformations observed within the first

Received for publication 25 May 1985 Accepted for publication 16 July 1985 three days of life are reported by a detailed 'verbatim' description according to standards given in a procedures manual. Additional material, such as $x$-rays, photographs, and necropsy reports, are not mandatory but frequent. Although the ECLAMC programme started in 1967, the inclusion of stillbirths only began in 1978, when the programme was extended to all births weighing $500 \mathrm{~g}$ or more. Since most skeletal dysplasias have a high mortality rate, the material for this study was restricted to the period beginning in 1978, when data for total births were available.

Skeletal dysplasia cases were retrieved from the ECLAMC files by means of code numbers 756.4 , 756.5 , and 756.6 of the eighth revision of the International Classification of Diseases. ${ }^{4}$ These refer to the osteochondrodysplasias as defined by the International Nomenclature of Constitutional Diseases of Bone, ${ }^{5}$ excluding the mesomelic dysplasias, Larsen syndrome, and otopalatodigital syndrome, but including bone dysplasias with a recognised metabolic defect.

All clinical descriptions and available documents were reviewed and final diagnoses were reached by agreement among the authors. Maternal and paternal ages at the time of birth of all cases of achondroplasia, both proven and questionable, without an achondroplastic parent, were compared with the parental ages of matched, normal, newborn babies, defined as the next like-sexed livebirth that occurred in the same hospital. In order to increase 
the sample size to an analysable level, all cases registered in the 1967 to 1983 period were considered. Differences were tested by the Wilcoxon test $^{6}$ with a significance level of 0.05 for the unilateral test.

\section{Results}

Skeletal dysplasias were diagnosed in 80 newborn babies out of 349470 births $(2 \cdot 3 / 10000)$, this prevalence rate being 2.0/10 000 (70/343 890) among livebirths and 17.9/10 $000(10 / 5580)$ among stillbirths.

A specific diagnosis of the type of skeletal dysplasia could not be made for 34 of 80 cases $(42 \%)$, mainly due to insufficient radiological documentation. Nevertheless, based on the available clinical description, family history, perinatal progress, and photographs, 21 of those 34 cases could be placed into one of three major diagnostic groups. Four cases with photographs were included in a group named 'thanatophoric dysplasia or achondrogenesis', since further differential diagnosis between these two categories was not possible. The other 17 cases without photographs were considered as questionable achondroplasia, 11 of them dying in the perinatal period and six of them living. All these patients were considered to be 'achondroplasia' by the attending paediatricians.

The observed prevalence rates for each specific diagnostic group, compared with those from the Italian Multicentre Monitoring System for Birth Defects $\left(\mathrm{IMMSBD}^{2}\right.$ ), are shown in table 1 . There is no type of skeletal dysplasia with a prevalence rate at birth as high as 1 in 10000 and the observed values are quite comparable between both programmes, the only exception probably being that of the lethal group of thanatophoric dysplasia and achondrogenesis, which is rarer in the ECLAMC (8/ $349470,0 \cdot 23 / 10000)$ than in the IMMSBD (18/ $217061,0 \cdot 83 / 10000$ ). However, if all 11 cases of questionable achondroplasia dying in the perinatal period in the ECLAMC were actually cases of thanatophoric dysplasia or achondrogenesis, the ECLAMC material would become comparable with that of the IMMSBD in this respect also, the frequency for this group then being 19/349 470 or $0 \cdot 54 / 10000$.

A clinical diagnosis of achondroplasia was made by the attending paediatrician in 33 of $80(41 \%)$ skeletal dysplasia cases, while only 14 of them $(42 \%)$ were still thought to have that condition after revision. On the other hand, only two cases of achondroplasia were not diagnosed as such by the paediatrician.

Mean paternal ages for the material from the 1967 to 1983 period were 37.71 years for 14 cases of achondroplasia with unaffected parents, 31.00 years for 13 cases of questionable achondroplasia not dying in the perinatal period, and 33.65 years for 21 cases of questionable achondroplasia dying in the perinatal period. Their matched control groups had mean paternal ages of $27.57,29.08$, and 29.71 years, respectively. Mean maternal ages, in the same order, were $27 \cdot 64,25 \cdot 31$, and 28.90 years for cases, and $24 \cdot 21,25 \cdot 08$, and $26 \cdot 52$ years for their controls. The Wilcoxon test showed that only within the sporadic achondroplasia group was the paternal age

TABLE 1 Birth prevalence rates (per 10000 ) for the skeletal dysplasias as reported in the present study (ECLAMC) and in the Italian multicentric registry (IMMSBD). ${ }^{2}$

\begin{tabular}{|c|c|c|c|c|}
\hline \multirow[t]{3}{*}{ Diagnostic groups } & \multirow{2}{*}{\multicolumn{2}{|c|}{$\begin{array}{l}\text { ECLAMC } \\
\text { Years 1978-1983 } \\
349470 \text { births }\end{array}$}} & \multirow{2}{*}{\multicolumn{2}{|c|}{$\begin{array}{l}\text { IMMSBD } \\
\text { Years 1978-1981 } \\
217061 \text { births }\end{array}$}} \\
\hline & & & & \\
\hline & No & Rate & No & Rate \\
\hline True achondroplasia & 16 & 0.46 & 8 & $0 \cdot 37$ \\
\hline Questionable achondroplasia, alive & 6 & $0 \cdot 17$ & - & - \\
\hline Questionable achondroplasia, dead & 11 & $0 \cdot 31$ & - & - \\
\hline Thanatophoric dysplasia & 3 & 0.09 & 13 & $0 \cdot 60$ \\
\hline Achondrogenesis & 1 & $0 \cdot 03$ & 5 & $0 \cdot 23$ \\
\hline Thanatophoric dysplasia or achondrogenesis & 4 & $0 \cdot 11$ & - & - \\
\hline Osteogenesis imperfecta & 15 & 0.43 & 8 & $0 \cdot 37$ \\
\hline Campomelic dysplasia & 3 & 0.09 & 1 & 0.05 \\
\hline Chondroectodermal dysplasia & 2 & 0.06 & 1 & 0.05 \\
\hline Chondrodysplasia punctata: Conradi-Hunermann & 1 & $0 \cdot 03$ & 2 & 0.09 \\
\hline Chondrodysplasia punctata: rhizomelic type & 1 & 0.03 & $\mathbf{0}$ & 0.00 \\
\hline Cleidocranial dysplasia & 1 & 0.03 & 0 & 0.00 \\
\hline Diastrophic dysplasia & 1 & $0 \cdot 03$ & 0 & 0.00 \\
\hline Hypophosphatasia & 1 & $0 \cdot 03$ & 0 & 0.00 \\
\hline Other, with specific diagnosis & 0 & $0 \cdot 00$ & 10 & 0.46 \\
\hline Other, without specific diagnosis & 13 & $0 \cdot 37$ & 5 & $0 \cdot 23$ \\
\hline Total & 80 & $2 \cdot 29$ & 53 & 2.44 \\
\hline
\end{tabular}


of cases (33.65 years) significantly different from the controls $(27.57$ years $)(t=-7.5, \mathrm{p}<0.05)$.

The observation that all 16 cases of proven achondroplasia registered in the 1978 to 1983 period came from only five of the 26 participating hospitals raised the question of whether the capability of making such a diagnosis was similar in all hospitals involved. Therefore, prevalence rates at birth and derived mutation rate per gamete were performed independently for each hospital (table 2). Among the five hospitals where at least one case of achondroplasia was detected, prevalence rates varied from 0.62 to $1 \cdot 90 / 10000$ births, with a mean value of 1.49. No case of achondroplasia was diagnosed among the 241749 births that occurred in the remaining 21 hospitals. This indicates an obvious under-registration, since even assuming a real prevalence rate of $0 \cdot 5 / 10000$ (16 cases in 349470 births for all 26 hospitals), 11 cases would be expected among the 241749 births from the 21 hospitals with no registered achondroplasia, their $99 \%$ confidence limits under Poisson distribution being three and 21 cases.

The calculated mutation rates for achondroplasia varied from 3.09 to $9.51 \times 10^{-5}$, with a mean value of 5.57 for the five hospitals mentioned above, and 1.72 for the total 26 hospitals in the ECLAMC sample.

There were 47 females and 32 males, plus an intersex stillbirth, among the skeletal dysplasia cases, which did not significantly differ from an expected $49 \%$ of females derived from the total birth sex ratio $\left(\chi_{1}^{2}=3.48, p>0.05\right)$. This analysis cannot be performed for each diagnostic category owing to small sample sizes.

The perinatal mortality rate for the skeletal dysplasias was $44 \%$ (35/80), with no deaths among the 16 proven achondroplasia cases, and $40 \%(6 / 15)$ for the osteogenesis imperfecta cases.

The frequency of parental consanguinity among the cases of skeletal dysplasia was close to $4 \%$ $(3 / 80)$, while the expected value for non-malformed control newborns is $0.8 \% .^{7}$ Those three cases? included one case of questionable achondroplasia not dying in the perinatal period and one case $\vec{\sigma}$ without a specific diagnosis, both with first cousin $\frac{\bar{\sigma}}{\sigma}$ parents, and one case of osteogenesis imperfecta with remote parental consanguinity.

A positive family history was recorded among some of the proven achondroplasia cases; five of the 16 mothers were also achondroplastics. There was $\vec{\circ}$ parental consanguinity in one case of osteogenesis $\overrightarrow{\vec{\omega}}$ imperfecta with a similarly affected brother, and $\stackrel{\omega}{\sigma}$ another case of osteogenesis imperfecta had an affected brother, mother, and maternal uncles and $\underline{0}$ cousins, compatible with a fully penetrant autosom- i al dominant trait.

\section{Discussion}

The prevalence rate at birth for the skeletal dysplasias reported in this paper $(2 \cdot 29 / 10000)$, as well as that published by Camera and Mastroiacovo ${ }^{2}(2 \cdot 44 /$ 10000 ), probably under-represent the true frequency of this group of birth defects. The frequency of 4.69 reported by Gustavson and Jorulf, ${ }^{1}$ and the 3.72 rate for the lethal skeletal dysplasias observed by Centa and Camera, ${ }^{8}$ seem to be closer to the actual frequency, even though those two series were obtained from a single hospital each with limited sample sizes: 14918 births for the former and 43060 births for the latter.

One indication of under-registration in the material presented here is the observed frequency of 1.12 (67/599 263) registered in the 1967 to 1977 period $^{9}$ compared with the 2.29 found in the 1978 to 1983 period reported here. This two-fold increase cannot be solely explained by the inclusion of stillbirths in the sample since 1978, since stillbirths only represent $13 \%(10 / 80)$ of the skeletal dysplasias and also our 17.9 prevalence rate among stillbirths is still much lower than the 71.9 reported by Camera and Mastroiacovo. ${ }^{2}$ A better knowledge of the skeletal

TABLE 2 Prevalence (per 10 000) and mutation $\left(\times 10^{-5}\right)$ rates for achondroplasia in five hospitals where such a diagnosis was made at least once, and in the rest of the ECLAMC material during the 1978 to 1983 period.

\begin{tabular}{|c|c|c|c|c|c|}
\hline \multirow[t]{2}{*}{ Place of diagnosis } & \multirow{2}{*}{$\begin{array}{l}\text { No of } \\
\text { births }\end{array}$} & \multicolumn{4}{|c|}{ Achondroplasia } \\
\hline & & $\begin{array}{l}\text { No of } \\
\text { cases }\end{array}$ & $\begin{array}{l}\text { Prevalence } \\
\text { rates }\end{array}$ & $\begin{array}{l}\text { Proportional } \\
\text { ratios }\end{array}$ & $\begin{array}{l}\text { Mutation } \\
\text { rates }\end{array}$ \\
\hline $\begin{array}{l}\text { Hospital } 303 \\
\text { Hospital F05 } \\
\text { Hospital } 501 \\
\text { Hospital } 308 \\
\text { Hospital E02 }\end{array}$ & $\begin{array}{ll}10 & 518 \\
31 & 940 \\
33 & 150 \\
15 & 925 \\
16 & 188\end{array}$ & $\begin{array}{l}2 \\
6 \\
5 \\
2 \\
1\end{array}$ & $\begin{array}{l}1.90 \\
1.88 \\
1.51 \\
1 \cdot 26 \\
0.62\end{array}$ & $\begin{array}{l}1: 5200 \\
1: 5300 \\
1: 6600 \\
1: 7900 \\
1: 16100\end{array}$ & $\begin{array}{l}9 \cdot 51 \\
6 \cdot 26 \\
6 \cdot 03 \\
3 \cdot 14 \\
3 \cdot 09\end{array}$ \\
\hline All five hospitals & 107721 & 16 & 1.49 & $1: 6700$ & $5 \cdot 57$ \\
\hline Remaining 21 hospitals & 241749 & 0 & - & - & - \\
\hline Total 26 hospitals & 349470 & 16 & 0.46 & $1: 21800$ & 1.72 \\
\hline
\end{tabular}


dysplasias by the physicians involved in this programme could be an important cause of the increase in their registered frequency. As this is a continuous and incomplete process, such an increase is expected to continue in the future simply as a consequence of improvement in the registration rate.

Since more than one million consecutive births have been examined by the ECLAMC programme from its start in 1967 to 1983 , at least one case of each known neonatal, recognisable type of skeletal dysplasia should have been diagnosed within this sample. However, even when two further diagnoses are added to the list observed in the 1978 to 1983 period, when the previous 1967 to 1977 period is also considered (one case of spondyloepiphyseal dysplasia and one of asphyxiating thoracic dysplasia), several specific diagnoses were not registered at all. Kniest dysplasia, first described in 1952, metatropic dysplasia, known since 1966, the Majewski short rib-polydactyly syndrome, described in 1971 , or the related Saldino-Noonan syndrome, described in 1972 , are some of the types of skeletal dysplasia that should have been present in this material and were not. ${ }^{10}$ This is another aspect of the above mentioned continuous and incomplete process of knowledge on the subject of the skeletal dysplasias.

Another indication of under-registration can be seen from the fact that all cases of achondroplasia, the best known of all skeletal dysplasias, were diagnosed in only five of the 26 maternity hospitals involved. The 1.49/10 000 rate in these five hospitals is a similar prevalence rate for achondroplasia to the 0.67 reported by Gustavson and Jorulf, ${ }^{1}$ and probably a more accurate one than the 0.46 rate obtained from the total ECLAMC sample or the 0.37 reported by Camera and Mastroiacovo. ${ }^{2}$ Since these five hospitals do not differ from the remaining sample with respect to parental ages or other demographic features that could explain a true higher frequency of achondroplasia, we can estimate that at least 36 cases of achondroplasia are missing among the 241749 births that occurred in the other 21 hospitals. Such an estimate would raise the prevalence rate of all skeletal dysplasias to 3.29/ 10000 births.

There is a recognised tendency to over-register achondroplasia, mostly due to the misdiagnosis of cases of thanatophoric dysplasia and achondrogenesis, ${ }^{11}$ which could also be seen in the material presented here. Forty-one percent of all cases (33/80) were originally diagnosed as achondroplasia, while less than half of them (14/33) were still diagnosed as such after revision of the documentation.

Those cases diagnosed as achondroplasia by the paediatrician, in which radiological documentation was insufficient, were placed into one of the non-specific diagnostic groups in order to keep them apart from the wholly unspecified skeletal dysplasia cases, where not even achondroplasia was suggested as a probable diagnosis by the attending paediatrician. The group of questionable achondroplasia with death in the perinatal period is likely to include cases with thanatophoric dysplasia and achondrogenesis, as was the case with those few patients with available $x$-ray films and photographs. On the other hand, the questionable achondroplasia group surviving the perinatal period could very well include some cases of true achondroplasia. However, this could not be substantiated by the analysis of paternal ages, which were not raised as would be expected if most cases within this group were actually achondroplasia.

The calculated mutation rates must be affected by the over- as well as by the under-registration of achondroplasia. Much higher values were obtained for the five hospitals where at least one case of achondroplasia was detected than for the total 26 hospitals. The latter is comparable to the mutation rate reported by Camera and Mastroiacovo. ${ }^{2}$ Even when higher prevalence rates for achondroplasia might be expected from South American populations because of their higher mean reproductive age, this should not affect the mutation rate. It is reasonable, then, to assume that the figures for the mutation rate published many years ago, ${ }^{12}$ when over-registration of achondroplasia was common because most of the differential diagnoses were still unknown, were in fact close to true values by compensating for the similarly frequent underregistration of this diagnosis at birth.

The lack of radiological data, follow up, and information on natural history does not allow a better sub-classification of cases in the osteogenesis imperfecta group. The observed $40 \%$ of perinatal mortality among them suggests that there is less than $40 \%$ of the 'lethal' type, since some cases of the 'severe' type are also expected to die in the perinatal period. ${ }^{13}$ Furthermore, if all 33 cases with osteogenesis imperfecta diagnosed during the longer period 1967 to 1983 in the ECLAMC programme are considered, two families are included with an autosomal dominant pedigree and four with a family history typical of autosomal recessive inheritance. This observation, with only $10 \%(4 / 33)$ of the osteogenesis imperfecta cases attributable to an autosomal recessive trait, agrees with the discovery of new biochemical types of autosomal dominant inheritance among the more severe cases of osteogenesis imperfecta. ${ }^{1314}$

This work was partially supported by the National 

Research Councils of Brazil $(\mathrm{CNPq})$ and Argentina
(CONICET).

\section{References}

1 Gustavson K-H, Jorulf H. Different types of osteochondrodysplasia in a consecutive series of newborns. Helv Paediatr Acta 1975;30:307-14.

${ }^{2}$ Camera G, Mastroiacovo P. Birth prevalence of skeletal dysplasias in the Italian Multicentric Monitoring System for Birth Defects. In: Papadatos CJ, Bartsocas CS, eds. Skeletal dysplasias. New York: Alan R Liss, 1982.

3 Castilla EE, Orioli IM. El Estudio Colaborativo Latinoamericano de Malformaciones Congénitas: ECLAMC/MONITOR. Interciência 1983;8:271-8.

4 World Health Organization. International classification of diseases. Eighth revision. Geneva: WHO, 1965

5 International Nomenclature of Constitutional Diseases of Bone. J Pediatr 1978;93:614-6.

6 Siegel S. Nonparametric statistics for the behavioral sciences. New York: McGraw-Hill, 1956.

7 Orioli IM, Castilla EE, Carvalho WP. Inbreeding in a SouthAmerican newborn series. Acta Anthropogenet 1982;6:45-55.
' Centa A, Camera G. Osteocondrodisplasie genotipiche letali del feto e del neonato. Genova: Stringa Editore, 1975.

9 Documento Final del I Curso Sudamericano de Vigilancia Epidemiologica de Malformaciones Congenitas y de la XVI Reunion Anual del Estudio Colaborativo Latinoamericano de Malformaciones Congenitas (ECLAMC). Montevideo: Ministerio de Salud Publica del Uruguay/OPS/OMS, 1985.

10 Maroteaux P. Les maladies osseuses de.l'enfant. Paris: Flammarion, 1982.

1 Curran JP, Sigmon BA, Opitz JM. Lethal forms of chondrodysplastic dwarfism. Pediatrics 1974:53:76-85.

12 Mørch ET. Chondrodystrophic dwarfs in Denmark. Copenhagen: Munksgaard, 1941.

${ }^{13}$ Maroteaux P, Cohen-Solal L. L'ostéogenése imparfaite létale. Ann Genet (Paris) 1984:27:11-5.

14 Byers PH, Bonadio J, Steinmann B. Invited editorial comment. Osteogenesis imperfecta: update and perspective. Am J Med î Genet 1984;17:429-35.

Correspondence and requests for reprints to Dr Iêda M Orioli, Cx Postal 68.011, 21910 Rio de Janeiro, Brazil. 